\title{
Theoretical Study on the Cultivation of Competitive Talents in Colleges and Universities in China
}

\author{
Yaohui Lin \\ Tan Kah Kee College \\ Xiamen University \\ Xiamen, China
}

\begin{abstract}
The University is to cultivate all-round development of talents. In recent years, with the mode of cultivating innovation and continuous improvement, social evaluation of the school began to develop in the direction of diversification, followed by more and more universities begin to pay attention to the brand and sports, increasing the degree of attention, with the level of school sports promotion, more students go to school by the occupation game platform to become the occupation basketball athletes. Especially, students through the college basketball league stage to CBA occupation field have become larger and larger, It's clear that we have capability of high level athletic talent cultivation in Colleges and universities in China, just lack of mining talents. As long as we give full play to the venues of colleges and universities, competitive sports will have great achievements. However, it is undeniable that the training of competitive talents in Colleges is still at the initial stage, we also have great potential to tap.
\end{abstract}

Keywords-university; competitive; talented person; foster

\section{INTRODUCTION}

The development of competitive sports in Colleges refers to follow the basic laws of education and the development of competitive sports, based on the motion with sports expertise and hobbies of the students, combine organized, planned, and targeted competitive sports training and activities to improve the athletic level of athletes on the basic of students complete their studies to achieve all-round development of the individual during training competitive talents in colleges.

Competitive sports in Colleges and universities need to accomplish many tasks in the process of school education. The first is to train students' cultural quality so that students can complete the courses and studies required by the school. Increase the competitive sports in this basis to enable students to develop their comprehensive qualities. In the development of competitive sports in China's universities, the rate of athletes' yield is relatively low. Most of athletes are trained through the platform of competitive sports school to become professional athletes. Although the competitive sports school has trained a large number of athletes for our country, it is undeniable that the disadvantages of competitive sports schools are beginning to appear. Especially when the athletes after a few years or even ten years of training found this road is go to nowhere, athletes have nothing in society, they are poor of cultural knowledge, some of them even have to engage in some service industries, their lives are difficult to be guaranteed, their own life is hard to secure. The appearance of this phenomenon has to arouse our attention. A single mode of delivering talent through competitive sports schools must be changed. By drawing on the training mode of foreign athletes, the advantages of competitive sports in Colleges and universities should be brought into full play, so that the training process of athletes can be completed in Colleges and universities as much as possible. On the one hand, the athletes do not delay their studies; on the other hand, in the process of training colleges and universities, athletes are trained effectively in the process of learning cultural knowledge. It plays an important role in understanding and using tactics in the match.

\section{The Present Situation OF The Training OF COMPETITIVE TALENTS IN COLLEGES AND UNIVERSITIES IN CHINA}

The connotation of competitive sports in Colleges and universities is mainly to recruit a certain number of students with potential for sports development through colleges and Universities. On the basis of the students' cultural teaching, the training of physical training should be carried out to fully develop the students' intelligence level and cognitive ability. Promoting the overall quality of students is a comprehensive and comprehensive process of education. Training is the quality of students in all aspects to promote the all-round development of students.

Because our country is vast in territory, the local conditions and customs are different, the universities in different areas have great differences in the training of competitive talents. Generally speaking, colleges and universities in the eastern part of China should have certain advantages in talent training compared with those in Western Universities. The economic and geographical position advantages attract more quality students, but also to attract relatively many excellent teachers in the Eastern University.

In recent years, colleges and universities have made remarkable achievements in the training of competitive talents. However, it is undeniable that there is still a big gap in the training of competitive talents in universities at this stage, and there is still a lot of room for improvement. At this stage, the mainly problems that restrict the training of competitive talents in Colleges and universities in China is 
the education system restricts the training of competitive talents in Colleges and Universities. Performance in Colleges and universities in the process of training competitive talents, cannot guarantee students' academic, in the process of training talents, pay too much attention to the cultivation of students' competitive ability, the importance of academic is not enough. How to ensure the quality of training during finish students study is an urgent problem for colleges and universities to solve. On the other hand, the current project of cultivating competitive talents in Colleges is relatively simple. Mainly include track and field, basketball, football, volleyball, swimming and other projects, relatively small number of other projects involved. The existence of this phenomenon has led to a lack of competitiveness in many projects and has affected competition unable to effectively select talent, affecting the healthy development of sports; we cannot effectively promote the development of the sport.

Most college coaches are teachers of the school. In addition to complete the normal teaching and education, engaged in the task of coaches. They also should use a great deal of energy in Teaching. Besides teaching, they should complete academic research, such as papers and subjects, and lead training. This kind of work intensity and measurement makes it difficult for coaches to have the energy to study, train and compete, and their teaching level is difficult to improve. Here are some in the sports team also hired coaches only in charge of lead a team, but most schools do not have such capital investment, which is the university athletic training has one of the important reasons for the bottleneck.

\section{ThE PRACTICAL SignifiCANCE OF THE TRAINING OF COMPETITIVE TALENTS IN COLLEGES AND UNIVERSITIES}

\section{A. The Cultivation of Competitive Talents in Colleges and Universities is Beneficial to the Sustainable Development of Competitive Talents in China}

The development of physical education is inseparable from education. Colleges and universities are the places where people can develop in an all-round way, and the strength of higher education directly determines the reserve forces of athletic talents. The inclusion of competitive sports in the scope of higher education, improved the training model of higher education, enriched the connotation of higher education, education and sports are perfect integration. In the training process of higher education, athletes not only complete training tasks, but also accept the edification of cultural knowledge and become people with connotations. Train athletes to become all-round development of people.

The development of higher education in China has been going through 30 years since 1987. In the process, whether the training mode of higher education meets the needs of the development of competitive sports has experienced disputes. However, from the development process of the past 30 years, more and more people have recognized the mode of cultivating competitive sports talents in Colleges. The main performance in the university athletic training number increased year by year, and the achievements are getting better and better, the Universiade record in constantly refreshed, more and more athletes to the occupation field through this platform, become the occupation athlete. This shows that the cultivation of competitive talents in Colleges and universities is developing in a good direction, and is conducive to the cultivation of competitive sports reserve talents.

\section{B. The Cultivation of Competitive Talents in Colleges and Universities is Conducive to the Reform and Innovation of Competitive Talents Training Mode}

For a long time China's competitive sports is carried out under the whole nation system, training mode can give athletes a way to a certain extent in the planned economy era, but in the modern market economy, the culture has begun to highlight the drawbacks of the model. On the one hand, because the sports employment market is relatively saturated, the employment of athletes have become a problem, athletes after retirement; there is no suitable unit placement. On the other hand, the majority of parents will not choose to send students to the sports school for training, there is a greater risk, few parents dare to take risks. The training mode of competitive sports in Colleges can solve this problem well. It enables athletes to train in school, which does not delay the study of culture courses, but also can develop in sports major. Through setting up three levels of training mode of primary school, middle school and University, athletes can not only have strong cultural quality, but also have high level of sports competition. Sports students with a high level of a higher level through the training team into the occupation, the level is not enough for students employment through the specialty, the training mode can effectively solve the problems of training and learning.

\section{The Cultivation of Competitive Talents in Colleges is Conducive to Enriching the Construction of Campus Culture}

College athletes are trained in their spare time in school, which can influence the students around the school to watch the school level or higher level competitions. More students can be attracted to participate in sports training, and improve the overall atmosphere of the school by watching the game. Thus it can be seen that the cultivation of competitive talents in Colleges and universities is conducive to enriching campus cultural life, affecting the students' sports atmosphere and promoting the development of physical education in Colleges and universities.

\section{THE COMPARISON OF COMPETITIVE TALENTS TRAINING BETWEEN U.S.A. AND CHINA}

\section{A. Training Mode of Competitive Talents in Colleges and Universities in China}

China University Sports Association was established in 1975. The main task of it is to promote the school sports work, promoting the quality of Physical Education, to cultivate all-round development of talents, organize large sports events between major universities. CUSA Staff from the initial 10 people to more than 40 people now. The number of staff has been increasing, the number of 
institutions has been increasing, and the division of labor has become increasingly clear. The competitive sports in Colleges have achieved some success in this atmosphere, but it is undeniable that there is still a gap of competitive sports between China and World power. At this stage, the management of competitive sports in China's colleges and universities mainly include enrollment, training and competition and Cultural Studies. Enrollment management is the premise of the enrollment rules and regulations specified by the Ministry of education in major universities, under the supervision and administration of the provincial education authorities, by the specific admissions department and the corresponding sports departments, in an open and transparent situation, the candidates for examination and selection of merit. The management of training and competition in Colleges and universities refers to the unified and standardized management of the enrolled students, so as to promote the students to achieve ideal results in training and competition. Different colleges and universities have different ways of managing students. Mainly concentrated management and decentralized management of the two management methods. Decentralized management means that students are dispersed in different majors after entering college. They attend classes together with ordinary students, and wait until the training and play games then meet again. Centralized management means that students are concentrated in a class after entering college, and athletes are trained and studied in a unified way. Each of these two management methods has its pros and cons. Centralized management is beneficial to study cultural courses according to the training time of athletes, decentralized learning is beneficial for athletes to communicate with other students, promoting the study of athletes' cultural courses. In the university teaching, each school should arrange the student's training and the study according to own different request

\section{B. Training Mode of Competitive Talents in American Colleges and Universities}

The United States is a world sports power, the success of American sports depends mainly on the medium and platform of the school, different levels of competition for the national transport of sports talent through the primary, secondary, University. Because of the long history of American school sports, in this process, the rules and regulations of school physical education are constantly improved, and finally a perfect competition and training system has been formed. Their students doing sports exercises during study to make a "both hands should be grasped and hard" situation.

Competitive sports in American universities develop for a long time. They farmed a good sports atmosphere. More people begin to pay attention to physical education in Colleges. Some athletes return to school to teach after finishing their sports career, continuously enhance the level of competitive sports in Colleges. On the other hand, colleges and universities provide good salary for coaches, and promote coaches to continuously improve their professional quality. If the coach is not responsible for the coaching process cannot reach the level of the school, then he likely to be fired after discussion. On the other hand, schools provide students with the motivation to participate in sports by providing scholarships for elite athletes, after some distinguished alumni have achieved successes, they will build sports venues for schools by means of donations. Such virtuous cycle continuously promotes the school sports ability promotion.

At this stage, the United States led by the International Olympic Committee, the individual sports federations as the executive level, relying on the United States University Sports Federation for the specific implementation of one of the competitive sports organizations. This successful development mode of competitive sports has made American college students the main force in the gold medal contest of the World University Games also provides a large number of athletic talents for American professional sports. This development model not only reduces the investment of state funds, but also provides more profitable economic returns for school athletes. It promotes the popularity of schools and expands their influence.

In the United States, there is no government department specializing in sports. The American College Athletic Federation was founded in 1906. After more than 100 years of growth and development, it has now become the most important management school sports association in the United States. The main task is to recruit, manage athletes, organizing events, publicity and media assistance. The United States University Sports Federation set up the Executive Committee, in the course of implementation according to the different stages of the development of physical education, according to the school's sports situation is divided into a Premier league, Secondary League and third league. This arrangement ensures that as many as possible schools participate in the competition, according to the level of the school, different points are divided into different levels of competition. This will make the game as exciting as possible, avoid a one-sided situation. Such a classification can also make schools at different levels compete for different purposes. The main purpose of a Premier League competition is to transport talent for the country. The main aims of other leagues are to promote the school sports atmosphere promote students' consciousness of exercise and realize their life value.

The Sports Federation of the United States is selffinancing and does not require government funding. The source of its financial gain is mainly through the proceeds of the matches broadcast. In addition, high levels of competition have attracted many sponsors, which is part of their income stream. The contradiction between learning and training is a problem faced by many colleges and Universities the American Sports Federation has a clear attitude towards this problem. First of all, ensure that the athlete's first identity is a student. This is basis for training and competition. No school can use an athlete as a tool for making money. Before an athlete take part in the competition, he or she must get a certain mark in the cultural class. Otherwise, even if the player has a high level of competitive ability, he or she cannot participate in the competition. This kind of regulation can make the athlete pay more attention to 
the study of the cultural lesson. The rules and regulations of the American Sports Federation are constantly improving. Generally speaking, the changes in the rules and regulations are mainly for the students' cultural study ensures that students can learn knowledge at school. The purpose of sports training is not only for athletic performance, but more important for the development of all-round quality of students. This is also the place where the institutions of higher learning in our country need further study

\section{THE INFLUENCE OF AMERICAN COMPETITIVE SPORTS MANAGEMENT ON CHINA}

Compare the structure of the University Sports Federation between China and U.S.A. Because of the late start, the Sports Association of China has a certain gap with the United States in terms of its management structure, staffing and the division of functions and powers. In contrast, the American College Sports Federation is a relatively independent institution, which can meet the needs of students' development and make plans for students' development needs. But the University Sports Federation in our country has more restrictions, especially the restriction of government departments, and it seems to be inefficient in the process of work. In the management, the United States Sports Federation more through the legal means to restrict all colleges and universities and sports teams, and our country is more through administrative means to intervene. There is no doubt that the United States still has certain advantages compared to our country in management, and our university sports management departments still have long way to go.

Although the China University Sports Federation is a non-profit organization, most of the staff members of the association are career development staff, and they are directly affected by the government. In the course of their work, they are affected by the dual roles of the Education Bureau and the Sports Bureau, and there is no real right in the actual management. The American College Sports Federation is also a non-profit social organization. In recent years, the University Sports Federation receives a certain amount of revenue by selling television rights. However, it is undeniable that there is still a gap between China and the American College Students Sports association. Facing the new situation and the new challenge, our university student sports association should fully study the practice from American. We should improve the organization and function of the Association Division, as far as possible to reduce the government departments to intervene in the association, give full play to the advantages of the sports association itself, and promote each sector's own subjectivity and autonomy of development.

\section{CONCLUSION}

The development stage of sports Federation in China is short, nominally although it is non-profit organizations, but most of the staff members belong to public institutions, in fact, there is no management of people, money, things. They all dominated by the government, and there is no contribution to the source of funds.
It is suggested that we should make full use of the mode of operation of the University Sports Federation, to further clarify the objectives, determine the work function, improve the management mechanism, in order to contribute to the development of competitive sports in China.

\section{REFERENCES}

[1] Chijian. Competitive sports management in American university. Beijing: people's sports press, 2005: 12-22

[2] Chijian. On the combination of competitive sports and higher education. journal of Beijing university of physical education, 2003, (2): $249-151$

[3] Ding ling, et al. on the reform of competitive system of high - level sports teams in China. journal of Wuhan institute of sports, 2000, 135 (2): 7-9

[4] $\mathrm{Xu} \mathrm{Li}$. the question and quest of some phenomena in the development of competitive sports in colleges and universities. report of Beijing sports university, 2010.6. 